Original article

\title{
Colectomy for patients with super obesity: current practice and surgical morbidity in the United States
}

\author{
Mohamed A. Abd El Aziz, M.B.B.Ch., Fabian Grass, M.D., \\ William Perry, M.B.Ch.B., M.P.H., Kevin T. Behm, M.D., Sherief F. Shawki, M.D., \\ David W. Larson, M.D., M.B.A., Kellie L. Mathis, M.D.** \\ Division of Colon and Rectal Surgery, Department of Surgery, Mayo Clinic, Rochester, Minnesota \\ Received 28 April 2020; accepted 13 June 2020
}

\begin{abstract}
Background: While minimally invasive surgery contributed to improved outcomes in bariatric surgery, less is known about current utilization trends and outcomes related to surgical technique for colorectal resections in super-obese patients (body mass index $\geq 50 \mathrm{~kg} / \mathrm{m}^{2}$ ).

Objective: The aim of this study was to compare surgical modalities and short-term outcomes of patients with super obesity who underwent elective colectomy in the United States.

Setting: A retrospective review was performed of patients with super obesity who underwent elective colectomy between 2012 to 2018 using the American College of Surgeons National Quality Improvement Program data pool.

Methods: Patients were categorized into an open, laparoscopic, or robotic group. Baseline characteristics and perioperative outcomes including 30-day complications and length of stay were compared between the 3 groups. Furthermore, utilization trends of surgical modalities were assessed. Results: Of 1199 patients, 338 (28.2\%) had open, 735 (61.3\%) laparoscopic, and 126 (10.5\%) robotic colectomy during the study period, primarily for colon cancer $(50.8 \%)$. Patients in the open group tended to have more baseline co-morbidities. Laparoscopic approach showed better riskadjusted outcomes compared with open for postoperative ileus (adjusted odds ratio [aOR]: .6, 95\% confidence interval [CI; .383-.965]), overall medical complications (aOR: .4, 95\%CI [.3-.8]), and length of stay (OR .6, 95\% CI [.394-.968]). Trend utilization showed increasing utilization of the robotic platform over the study period, which was associated with less unplanned conversion to open (aOR .417, 95\% CI [.199-.872]).

Conclusion: Laparoscopic colectomy provides advantageous outcomes over open surgery for colectomy in super-obese patients. The robotic platform has been increasingly used over time, and potential benefits need to be further studied. (Surg Obes Relat Dis 2020;16:1764-1769.) (C) 2020 American Society for Bariatric Surgery. Published by Elsevier Inc. All rights reserved.
\end{abstract}

Obesity represents a technical challenge for minimally invasive surgery (MIS) due to a lack of working space, exposure, weight, and fragility of highly vascularized fat

\footnotetext{
* Correspondence: Kellie L. Mathis, M.D., Division of Colon and Rectal Surgery, Department of Surgery, Mayo Clinic, 200 First St. Southwest, Rochester, MN 55905.
}

tissue [1,2]. However, short-term outcomes appear to be better after MIS than after open surgery in obese patients (body mass index $[\mathrm{BMI}] \geq 30 \mathrm{~kg} / \mathrm{m}^{2}$ ) [3]. Furthermore, it has been

E-mail address: Mathis.Kellie@mayo.edu (K.L. Mathis). 
proposed that the robotic platform may help overcome some of the limitations of laparoscopy through improved navigation, dexterity, and visualization [3-5].

Super-obese patients (BMI $\geq 50 \mathrm{~kg} / \mathrm{m}^{2}$ ) represent a particularly complex subgroup of patients from a medical, metabolic, and surgical perspective [1,2,6-8]. The rising preponderance of super obesity in the United States represents a challenge for nondeferrable nonbariatricrelated procedures $[1,9,10]$. Furthermore, MIS in these patients requires a high degree of expertise and technical skills. While MIS contributed to improved outcomes in bariatric surgery [11,12], less is known about current utilization trends and outcomes related to surgical technique for colorectal resections in super-obese patients.

This study aimed to evaluate surgical modality utilization trends and short-term outcomes in patients with super obesity undergoing elective colectomy.

\section{Methods}

The American College of Surgeons National Quality Improvement Program database (ACS-NSQIP) was interrogated to assess patients who underwent an elective colectomy between 2012 and 2018. ACS-NSQIP is a repeatedly validated, national data pool developed for quality improvement purposes representing a risk-adjusted and outcome-based program. In brief, data abstraction from all participant sites is conducted by trained abstractors and a random sample of $20 \%$ of patients from each contributing institution is included in the final data set [13]. This study was considered exempt from institutional review board approval.

Participant User Files of ACS-NSQIP were merged with their corresponding "Targeted Colectomy" files. Patients with super obesity (BMI $\geq 50 \mathrm{~kg} / \mathrm{m}^{2}$ ) who underwent elective colectomy for any indication using the associated specific Current Procedure Terminology codes (44140, 44141, 44143, 44144, 44145, 44146, 44147, 44150, 44160, 44204, 44205, 44206, 44207, 44208, 44210) were identified. Patients with no operative approach available at the "COL-APPROACH" variable accessed through the targeted colectomy files and patients undergoing an urgent or emergent operation were excluded. Subsequently, patients were categorized according to the operative modality into open, laparoscopic, and robotic groups.

Baseline demographic, anthropometric, and perioperative data were compared between the 3 groups. Surgical indications were categorized as cancer, inflammatory bowel disease, diverticular disorders and others (such as benign neoplasms). Further assessed were conversion to open rate, various postoperative medical and surgical 30-day complications according to standard ACS-NSQIP definitions and length of index hospital stay (with prolonged length of stay defined upper quartile of the entire cohort
( $>6 \mathrm{~d}$ ). Utilization trends by calendar year of the inclusion period were also assessed.

\section{Statistical analysis}

Data were reported in frequencies and percentages for categoric variables, or median (interquartile range) for continuous variables. Multigroup comparisons were performed using the $\mathrm{X}^{2}$ test for categoric variables and the independent Samples Kruskal-Wallis Test for continuous variables. Outcomes with an alpha level of $<.1$ and event rate $\geq 10$ for all 3 approaches in the univariate analysis were further examined using multivariate binary logistic regression. A $P$ value of $<.05$ was considered significant. Utilization trends of the different surgical approaches over time were assessed using linear regression. The analysis was conducted using the Statistical Package for Social Sciences (SPSS, Version 25; SPSS, Inc., Armonk, NY, USA).

\section{Results}

Of 1199 patients identified, 338 (28.2\%) had an open colectomy, $735(61.3 \%)$ had a laparoscopic colectomy, and $126(10.5 \%)$ had a robotic colectomy. The most common indication for surgery was colon cancer $(50.8 \%)$, followed by other diseases (23.4\%), diverticular disease $(22.4 \%)$, and inflammatory bowel disease $(3.3 \%)$.

Patients undergoing open surgery tended to be older and presented with more confounding co-morbidities, such as type 2 diabetes and cardiovascular co-morbidities (Table 1).

While surgical duration was significantly higher in the robotic group, conversion rate was lower in the robotic compared with the laparoscopic group $(13.5 \%$ versus $17.6 \%$, adjusted odds ratio [aOR]: $.4 ; 95 \%$ confidence interval [CI; .2-.9]).

Patients treated by open surgery were more likely to experience overall complications, surgical complications, and medical complications. More specifically, they were more likely to suffer surgical site infection, postoperative ileus, systemic sepsis, pneumonia, unplanned intubation, failure to wean mechanical ventilation within 48 hours, progressive renal insufficiency, acute renal failure, urinary tract infection, myocardial infarction, prolonged length of stay $>6$ days, and death within 30 days (Table 2).

After adjusting for baseline characteristics and risk factors, laparoscopy was associated with decreased postoperative ileus, fewer overall medical complications, and fewer patients with a length of stay $>6$ days compared with the open approach. Robotic surgery was associated with a decreased rate of prolonged length of stay $>6$ days compared with the open approach (Table 3).

Utilization analysis over time revealed a trend toward increasing utilization of the robotic modality at the expense of open surgery. The laparoscopic approach was the most used and remained stable over time (Fig. 1). 
Table 1

Demographic characteristics, anthropometric, and baseline characteristics

\begin{tabular}{|c|c|c|c|c|c|}
\hline & Open $n=338$ & Laparoscopic $\mathrm{n}=735$ & Robotic $\mathrm{n}=126$ & Total $\mathrm{n}=1199$ & $P$ value* \\
\hline Male & $106(31.4 \%)$ & $260(35.4 \%)$ & $52(41.3 \%)$ & $418(34.9 \%)$ & .1 \\
\hline Age & $59(50-67)$ & $56(48-64)$ & $54(47-64)$ & $57(49-65)$ & .001 \\
\hline BMI & $53.6(51-58)$ & $54(52-58)$ & $54(51-57)$ & $54(52-58)$ & .5 \\
\hline Race & & & & & .8 \\
\hline White & $245(72.5 \%)$ & $513(69.8 \%)$ & $96(76.2 \%)$ & $854(71.2 \%)$ & \\
\hline Black & $58(17.2 \%)$ & $136(18.5 \%)$ & $23(18.3 \%)$ & $217(18.1 \%)$ & \\
\hline Asian & $2(.6 \%)$ & $7(1.0 \%)$ & 0 & $9(.8 \%)$ & \\
\hline Others & $3(.9 \%)$ & $10(13 \%)$ & 0 & $13(11 \%)$ & \\
\hline Unknown & $30(8.9 \%)$ & $69(9.4 \%)$ & $7(5.6 \%)$ & $106(8.8 \%)$ & \\
\hline Hispanic & $21(6.2 \%)$ & $48(6.5 \%)$ & $8(6.3 \%)$ & $77(6.4 \%)$ & .8 \\
\hline Underlying disease & & & & & $<.0001$ \\
\hline Colon cancer & $180(53.3 \%)$ & $360(49 \%)$ & $69(54.8 \%)$ & $609(50.8 \%)$ & \\
\hline IBD & $11(3.3 \%)$ & $27(3.7 \%)$ & $2(1.6 \%)$ & $40(3.3 \%)$ & \\
\hline Diverticular disorder & $54(16 \%)$ & $172(23.4 \%)$ & $43(34.1 \%)$ & $269(22.4 \%)$ & \\
\hline Others & $93(27.5 \%)$ & $176(23.9 \%)$ & $12(9.5 \%)$ & $281(23.4 \%)$ & \\
\hline $\mathrm{T} 2 \mathrm{D}$ & $126(37.3 \%)$ & $218(29.7 \%)$ & $38(30.2 \%)$ & $382(31.9 \%)$ & .04 \\
\hline \multicolumn{6}{|l|}{ Cardiopulmonary } \\
\hline Dyspnea & $84(24.9 \%)$ & $126(17.1 \%)$ & $13(10.3 \%)$ & $223(18.6 \%)$ & $<.0001$ \\
\hline COPD & $24(7.1 \%)$ & $49(6.7 \%)$ & $6(4.8 \%)$ & $79(6.6 \%)$ & .7 \\
\hline $\mathrm{CHF}$ & $8(2.4 \%)$ & $9(1.2 \%)$ & 0 & $17(1.4 \%)$ & .1 \\
\hline HTN & $237(70.1 \%)$ & $486(66.1 \%)$ & $88(69.8 \%)$ & $811(67.6 \%)$ & .4 \\
\hline Functional status & & & & & .04 \\
\hline Independent & $318(94.1 \%)$ & $714(97.1 \%)$ & $122(96.8 \%)$ & $1154(96.2 \%)$ & \\
\hline Unknown & $2(.6 \%)$ & 0 & 0 & $2(.2 \%)$ & \\
\hline On hemodialysis & $1(.3 \%)$ & $2(.3 \%)$ & 0 & $3(.3 \%)$ & .8 \\
\hline \multicolumn{6}{|l|}{ Hematologic } \\
\hline Bleeding disorder & $14(4.1 \%)$ & $16(2.2 \%)$ & $7(5.6 \%)$ & $37(3.1 \%)$ & .053 \\
\hline Hematocrit (\%) & $37.5(34-41)$ & $39(35-42)$ & $39(35-42)$ & $39(35-42)$ & $<.0001$ \\
\hline Platelets $(1000 / \mu \mathrm{L})$ & $251(193-315)$ & $272(221-320)$ & $293(233-332)$ & $265(218-318)$ & .004 \\
\hline $\begin{array}{l}\text { Transfusion } \geq 1 \mathrm{pRBC} \text { within } 72 \mathrm{hr} \text { of } \\
\text { surgery }\end{array}$ & $6(1.8 \%)$ & $3(.4 \%)$ & 0 & $9(.8 \%)$ & .03 \\
\hline \multicolumn{6}{|l|}{ Nutritional status } \\
\hline$>10 \%$ loss of body weight in last $6 \mathrm{mo}$ & $4(1.2 \%)$ & $7(1 \%)$ & 0 & $11(.9 \%)$ & .5 \\
\hline Albumin & $3.7(3.3-4)$ & $3.8(3.4-4.1)$ & $3.8(3.4-4.1)$ & $3.8(3.4-4.1)$ & .03 \\
\hline Disseminated cancer & $25(4.7 \%)$ & $24(3.3 \%)$ & $3(2.4 \%)$ & $52(4.3 \%)$ & .004 \\
\hline Chronic steroid use & $19(5.6 \%)$ & $37(5 \%)$ & $6(4.8 \%)$ & $62(5.2 \%)$ & .9 \\
\hline Operation time, min & $185(133-277)$ & $190(141-270)$ & $263(209-316)$ & $197(143-281)$ & $<.0001$ \\
\hline
\end{tabular}

$\mathrm{BMI}=$ body mass index; IBD = inflammatory bowel disease; $\mathrm{T} 2 \mathrm{D}=$ type 2 diabetes; $\mathrm{COPD}=$ chronic obstructive pulmonary disease; $\mathrm{CHF}=$ congestive heart failure; HTN = hypertension requiring medication; ASA = American Society of Anesthesiologists; $\mathrm{LOS}=$ length of stay; $\mathrm{pRBC}=$ packed red blood cells.

Bold indicates significant $P$ values.

* Derived from Independent Samples Kruskal-Wallis Test for continuous variables, and $\mathrm{X}^{2}$ test for categoric variables.

\section{Discussion}

This representative large-scale study demonstrated beneficial outcomes associated with laparoscopy over open surgery for colonic resections in the critical patient population with super obesity. The robotic approach achieved outcomes similar to laparoscopy, with the statistical insignificance being likely related to the comparatively small sample size and associated event rates because of the novelty of the platform. While robotic cases were significantly longer, conversion rate was lower than for laparoscopic procedures. While the robotic modality was increasingly used at the expense of open surgery, laparoscopy remained the preponderant platform over the study period.
The increasing incidence of obesity among patients with colorectal diseases is a reflection of the obesity epidemic in the United States [14-16]. Obesity itself is a predisposing factor for colon cancer [17-19] and represents a wellknown risk factor for postoperative adverse events [2022]. Super obesity was repeatedly identified as the strongest predictor of perioperative morbidity for different intraabdominal operations [23,24]. Reasons for worse outcomes are multifactorial and include co-morbidities, compromised intraabdominal working space associated with bulky omentum, mesentery and abdominal wall, and suboptimal visualization of highly vascularized fat wrapped anatomic structures [6-8,25-29]. This imposes significant 
Table 2

Postoperative complications

\begin{tabular}{|c|c|c|c|c|c|}
\hline & Open $\mathrm{n}=338$ & Laparoscopic $\mathrm{n}=735$ & Robotic $\mathrm{n}=126$ & Total $\mathrm{n}=1199$ & $P$ value* \\
\hline Any complication ${ }^{\dagger}$ & $144(42.7 \%)$ & $252(34.4 \%)$ & $39(31.2 \%)$ & $435(36.4 \%)$ & .014 \\
\hline Any surgical complication ${ }^{\ddagger}$ & $131(38.9 \%)$ & $235(32.1 \%)$ & $37(29.6 \%)$ & $403(33.8 \%)$ & .055 \\
\hline SSI & $69(20.4 \%)$ & $82(11.2 \%)$ & $15(11.9 \%)$ & $166(13.8 \%)$ & $<.0001$ \\
\hline Superficial SSI & $37(10.9 \%)$ & $45(6.1 \%)$ & $9(7.1 \%)$ & $91(7.6 \%)$ & .02 \\
\hline Deep SSI & $17(5 \%)$ & $13(1.8 \%)$ & $2(1.6 \%)$ & $32(2.7 \%)$ & .006 \\
\hline Organ space SSI & $21(6.2 \%)$ & $27(3.7 \%)$ & $7(5.6 \%)$ & $55(4.6 \%)$ & .2 \\
\hline Wound disruption & $9(2.7 \%)$ & $13(1.8 \%)$ & $1(.8 \%)$ & $23(1.9 \%)$ & .4 \\
\hline Unplanned reoperation & $34(10.1 \%)$ & $41(5.6 \%)$ & $8(6.3 \%)$ & $83(6.9 \%)$ & .03 \\
\hline Leak & $15(4.4 \%)$ & $21(2.9 \%)$ & $3(2.4 \%)$ & $39(3.3 \%)$ & .3 \\
\hline Ileus & $70(20.7 \%)$ & $77(10.5 \%)$ & $17(13.5 \%)$ & $164(13.7 \%)$ & $<.0001$ \\
\hline Unplanned conversion to open & NA & $129(17.6 \%)$ & $17(13.5 \%)$ & $146(12.2 \%)$ & $<.0001$ \\
\hline Systemic sepsis & $35(10.4 \%)$ & $33(4.5 \%)$ & $5(4 \%)$ & $73(6.1 \%)$ & .001 \\
\hline Sepsis & $18(5.3 \%)$ & $26(3.5 \%)$ & $4(3.2 \%)$ & $48(4 \%)$ & .3 \\
\hline Septic shock & $19(5.6 \%)$ & $9(1.2 \%)$ & $1(.8 \%)$ & $29(2.4 \%)$ & $<.0001$ \\
\hline Any medical complication & $60(17.8 \%)$ & $47(6.4 \%)$ & $10(7.9 \%)$ & $117(9.8 \%)$ & $<.0001$ \\
\hline Any respiratory complication & $29(8.6 \%)$ & $19(2.6 \%)$ & $3(2.4 \%)$ & $51(4.3 \%)$ & $<.0001$ \\
\hline Pneumonia & $9(2.7 \%)$ & $7(1 \%)$ & 0 & $16(1.3 \%)$ & .03 \\
\hline Unplanned intubation & $17(5 \%)$ & $11(1.5 \%)$ & $2(1.6 \%)$ & $30(2.5 \%)$ & .002 \\
\hline On ventilator $>48 \mathrm{hr}$ & $21(6.2 \%)$ & $10(1.4 \%)$ & $1(.8 \%)$ & $32(2.7 \%)$ & $<.0001$ \\
\hline VTE & $14(4.1 \%)$ & $11(1.5 \%)$ & $2(1.6 \%)$ & $27(2.3 \%)$ & .022 \\
\hline $\mathrm{PE}$ & $8(2.4 \%)$ & $8(1.1 \%)$ & $1(.8 \%)$ & $17(1.4 \%)$ & .2 \\
\hline DVT & $7(2.1 \%)$ & $5(.7 \%)$ & $1(.8 \%)$ & $13(1.1 \%)$ & .117 \\
\hline Any renal complication & $15(4.4 \%)$ & $8(1.1 \%)$ & $5(4 \%)$ & $28(2.3 \%)$ & .001 \\
\hline Progressive renal insufficiency & $7(2.1 \%)$ & $5(.7 \%)$ & $5(4 \%)$ & $17(1.4 \%)$ & .008 \\
\hline Acute renal failure & $8(2.4 \%)$ & $4(.5 \%)$ & 0 & $12(1 \%)$ & .01 \\
\hline UTI & $20(5.9 \%)$ & $18(2.4 \%)$ & $4(3.2 \%)$ & $42(3.5 \%)$ & .02 \\
\hline Any cardiac complication & $9(2.7 \%)$ & $3(.4 \%)$ & $1(.8 \%)$ & $13(1.1 \%)$ & .004 \\
\hline Cardiac arrest requiring $\mathrm{CPR}$ & $5(1.5 \%)$ & $3(.4 \%)$ & 0 & $8(.7 \%)$ & .08 \\
\hline MI & $6(1.8 \%)$ & 0 & $1(.8 \%)$ & $7(.6 \%)$ & .002 \\
\hline LOS, d & $6(5-9)$ & $4(3-6)$ & $4(3-6)$ & $5(3-7)$ & $<.0001$ \\
\hline LOS $>6 \mathrm{~d}$ & $96(34.7 \%)$ & $98(16.9 \%)$ & $16(18.8 \%)$ & $210(22.3 \%)$ & $<.0001$ \\
\hline Unplanned readmission & $50(14.8 \%)$ & $82(11.2 \%)$ & $12(9.5 \%)$ & $144(12 \%)$ & .124 \\
\hline Death within $30 \mathrm{~d}$ & $9(2.7 \%)$ & $5(.7 \%)$ & $2(1.6 \%)$ & $16(1.3 \%)$ & .03 \\
\hline
\end{tabular}

$\mathrm{SSI}=$ surgical site infection; VTE = venous thromboembolism; $\mathrm{PE}=$ pulmonary embolism; $\mathrm{DVT}=$ deep venous thrombosis; $\mathrm{UTI}=$ urinary tract infection; $\mathrm{CPR}=$ cardiopulmonary resuscitation; $\mathrm{MI}=$ myocardial infarction; $\mathrm{LOS}=$ length of stay.

Bold indicates significant $P$ values.

NB: the numbers do not add up because patients experiencing multiple complications were accounted for as one.

* Derived from independent Samples Kruskal-Wallis test for continuous variables and $\mathrm{X}^{2}$ test for categoric variables.

${ }^{\dagger}$ Any complication: any surgical and/or any medical complication.

¥ Any surgical complication includes superficial SSI, deep SSI, organ/space SSI, ileus, leak, unplanned reoperation, death within 30 days, unplanned conversion to open, sepsis, septic shock, and/or wound disruption.

$\S$ Any medical complication includes: pneumonia, unplanned intubation, on a mechanical ventilator for $>48$ hours, PE, DVT, progressive renal failure, acute renal failure, UTI, cardiac arrest requiring CPR, or MI.

challenges on surgical conduct and puts these patients at higher risk of surgical site infections, organ space infections, sepsis, and septic shock [10,30]. Furthermore, the preponderance of co-morbidities in super-obese patients increases the risk of potentially devastating cardiopulmonary complications [31-33].

In this analysis, MIS colectomy appeared to be relatively safe with lower rates of overall, specific surgical and medical morbidity alongside a shorter length of stay compared with the open approach. The high rate of postoperative septic complications after open surgery is of concern but in line with a former ACS-NSQIP analysis, which found that obesity (BMI $>30 \mathrm{~kg} / \mathrm{m}^{2}$ ) was an independent risk factor for postoperative sepsis $[5,24]$. The overall complication rate of $34.4 \%$ for laparoscopic and $31.2 \%$ for robotic surgery compares well with a previous analysis that found a rate of $41.4 \%$ after minimally invasive colectomy [10]. However, the same study reported higher rates of surgical site infection (24.2\% versus $11.2 \%$ ), anastomotic leak ( $4.8 \%$ versus $2.9 \%$ ), and postoperative ileus ( $10.5 \%$ versus $6.5 \%$ ) after laparoscopic surgery than our study.

ACS-NSQIP does not provide information about training or specialization of operating surgeons, which may have differed among the 3 modalities. This is important because there is growing evidence associating MIS fellowship training with improved outcomes [34,35]. Furthermore, indications for surgery were not equally distributed between the 3 groups, which has to be considered when comparing 
Table 3

Multivariate analysis

\begin{tabular}{|c|c|c|c|c|c|c|}
\hline & \multicolumn{2}{|c|}{ Laparoscopic versus open } & \multicolumn{2}{|c|}{ Robotic versus open } & \multicolumn{2}{|c|}{ Robotic versus laparoscopic } \\
\hline & $\mathrm{OR}^{*}(95 \% \mathrm{CI})$ & $P$ value & $\mathrm{OR}^{*}(95 \% \mathrm{CI})$ & $P$ value & $\mathrm{OR}^{*}(95 \% \mathrm{CI})$ & $P$ value \\
\hline Any complication ${ }^{\dagger}$ & $.9(.6-1.3)$ & .5 & $.6(.3-1)$ & .066 & $.668(.397-1.24)$ & .129 \\
\hline Any surgical complication & $.962(.671-1.4)$ & .8 & $.6(.4-1.1)$ & .1 & $.663(.391-1.25)$ & .128 \\
\hline Any SSI & $.656(.409-1.051)$ & .08 & $.525(.242-1.136)$ & .102 & $.793(.368-1.705)$ & .552 \\
\hline Unplanned reoperation & $.7(.379-1.295)$ & .257 & $.864(.342-2.184)$ & .757 & $1.2(.489-2.997)$ & 679 \\
\hline Ileus & $.6(.383-.965)$ & .035 & $.704(.348-1.423)$ & .328 & $1.2(.619-2.415)$ & .563 \\
\hline Unplanned conversion to open & NA & & NA & & $.417(.199-.872)$ & .02 \\
\hline Any medical complication ${ }^{8}$ & $.4(.3-.8)$ & .004 & $.5(.2-1.4)$ & 0.2 & $1(.4-2.6)$ & .972 \\
\hline $\operatorname{LOS}>6 \mathrm{~d}$ & $.618(.394-.968)$ & .035 & .375 (.171-.822) & .014 & $.608(.283-1.308)$ & .203 \\
\hline
\end{tabular}

$\mathrm{OR}=$ odds ratio; $\mathrm{CI}=$ confidence interval; $\mathrm{SSI}=$ surgical site infection; $\mathrm{LOS}=$ length of stay; NA = not applicable.

Bold indicates significant $P$ values.

* Adjusted for age, type 2 diabetes, dyspnea, preoperative functional health status, disseminated cancer, open wound/wound infection, bleeding disorder, transfusion $\geq 1$ unit packed red blood cells in 72 hours before surgery, American Society of Anesthesiologists class, wound class, and total operation time.

${ }^{\dagger}$ Any complication: any surgical and/or any medical complication.

${ }^{\ddagger}$ Any surgical complication includes: superficial SSI, deep SSI, organ/space SSI, ileus, leak, unplanned reoperation, death within 30 days, unplanned conversion to open, sepsis, septic shock, and/or wound disruption.

$\S^{\S}$ Any medical complication includes: pneumonia, unplanned intubation, on a mechanical ventilator for $>48$ hours, pulmonary embolism, deep venous thrombosis, progressive renal failure, acute renal failure, urinary tract infection , cardiac arrest requiring cardiopulmonary resuscitation, or myocardial infarction.

duration of surgery and postoperative outcomes. Nevertheless, the results of the present study suggest treatment of these complex high-risk patients in specialized settings providing a high degree of MIS experience.

A robotic approach showed decreased conversion rate compared with laparoscopic colectomy $(13.5 \%$ versus $17.6 \%, P<.0001$; aOR .417 ; $95 \% \mathrm{CI}(.199-.872)$. This is consistent with previous studies suggesting robotics potential to overcome limitations of laparoscopy in bariatric patients because of its 3-dimensional visualization and 360 articulation [12]. Despite a decreased conversion rate, the

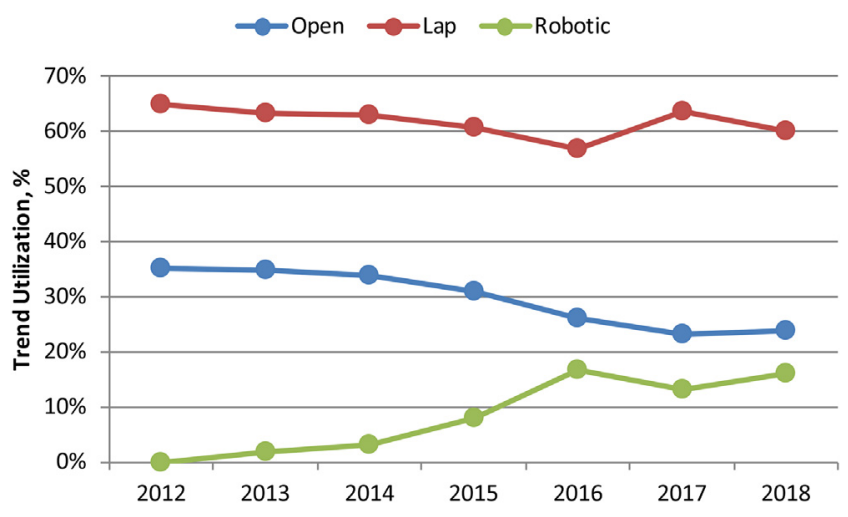

Fig. 1. Trend utilization of the different operative modalities between 2012 and 2018 for patients with super obesity. Open approach: the utilization of the open approach was $35.1 \%$ in 2012 and decreased to $23.8 \%$ in 2018 (slope $-2.4 \%$ per year; $95 \%$ CI $[-3.7 \%$ to $-1 \%], P$ value $=.001$ ). Laparoscopic approach: the utilization of the laparoscopic approach was $64.9 \%$ in 2012 and decreased to $60.2 \%$ in 2018 (slope - $.6 \%$ per year; 95\% CI [ $-2 \%$ to $.9 \%$ ], $P$ value .435$)$. Robotic approach: the utilization of the robotic approach was $0 \%$ in 2012 and increased to $16 \%$ in 2018, (slope $2.9 \%$ per year; $95 \%$ CI $[2 \%-3.8 \%], P$ value $<.0001)$. present study could not demonstrate significantly improved short-term postoperative outcomes. The reasons for this observation may be multifactorial and related to type II error (small sample size of the robotic group) and early experience (prolonged surgical duration).

Utilization analysis over time revealed a significant increase in robotic approach at the expense of open surgery and unchanged trends with the laparoscopic approach. These results suggest the robotic platform has allowed further uptake of minimally invasive approaches to colectomy and the associated advantages in this challenging group of patients.

This analysis is limited by its retrospective design and natural variance of data quality in a large nationwide data set. The study is also prone to selection bias, as shown by the comparatively sicker patient cohort of patients undergoing open surgery, in which co-morbidities potentially precluded them from undergoing a minimally invasive approach. This was addressed by adjusting outcomes through multivariable regression analysis. ACS-NSQIP includes only $20 \%$ of patients of participating centers. However, these patients represent a random sample. Furthermore, long-term outcomes and surgical specifics including extent of resection and type of dissection (high tie, low, tie, mesocolic), anastomosis configuration and completeness of MIS approach (extra versus intracorporeal vessel dissection, mobilization, transection, anastomosis) are not available in the ACS-NSQIP data pool. Finally, differences in pre-, peri- and postoperative care, setting and case volumes of participating institutions, and surgeons' experience are not captured. It is unknown whether these potential confounders were equally distributed between the 3 groups. 


\section{Conclusion}

Patients with superobesity represent a high-risk population from a medical and surgical standpoint. MIS approaches for elective colectomy appear to be safe and to provide benefits regarding overall and specific postoperative morbidity, length of stay, and 30-day mortality. The robotic platform may facilitate implementation of MIS modalities for super-obese patients evidenced by the increased utilization associated with a concomitant decrease in open approach. Treatment in specialized settings providing a high degree of MIS expertise likely contributes to better outcomes.

\section{Disclosures}

The authors have no commercial associations that might be a conflict of interest in relation to this article.

\section{References}

[1] Schorge JO. Minimally invasive surgery in morbidly obese women. Obstet Gynecol 2020;135(1):199-210.

[2] Scheib SA, Tanner III E, Green IC, Fader AN. Laparoscopy in the morbidly obese: physiologic considerations and surgical techniques to optimize success. J Minim Invasive Gynecol 2014;21(2):182-95.

[3] Juo YY, Hyder O, Haider AH, Camp M, Lidor A, Ahuja N. Is minimally invasive colon resection better than traditional approaches? First comprehensive national examination with propensity score matching. JAMA Surg 2014;149(2):177-84.

[4] Duchalais E, Machairas N, Kelley SR, et al. Does obesity impact postoperative outcomes following robotic-assisted surgery for rectal cancer? Surg Endosc 2018;32(12):4886-92.

[5] Harr JN, Haskins IN, Amdur RL, Agarwal S, Obias V. The effect of obesity on laparoscopic and robotic-assisted colorectal surgery outcomes: an ACS-NSQIP database analysis. J Robot Surg 2017;12(2):317-23.

[6] Van Gaal LF, Mertens IL, De Block CE. Mechanisms linking obesity with cardiovascular disease. Nature 2006;444(7121):875-80.

[7] Keskek SO, Kursun O, Ortoglu G, Bankir M, Tuzun Z, Saler T. Obesity without comorbidity may also lead to non-thyroidal illness syndrome. Adv Clin Med Exp 2018;27(11):1515-20.

[8] Scott HA, Wood LG, Gibson PG. Role of obesity in asthma: mechanisms and management strategies. Curr Allergy Asthma Rep 2017;17(8):53.

[9] Panteleimonitis S, Popeskou S, Harper M, et al. Minimally invasive colorectal surgery in the morbid obese: does size really matter? Surg Endosc 2018;32(8):3486-94.

[10] Champagne BJ, Nishtala M, Brady JT, et al. Laparoscopic colectomy in the obese, morbidly obese, and super morbidly obese: when does weight matter? Int J Colorectal Dis 2017;32(10):1447-51.

[11] Buchs NC, Azagury DE, Pugin F, et al. Roux-en-Y gastric bypass for super obese patients: what approach? Int J Med Robot 2016;12(2):276-82.

[12] Buchs NC, Pugin F, Chassot G, Volonte F, Koutny-Fong P, Hagen ME, Morel P. Robot-assisted Roux-en-Y gastric bypass for super obese patients: a comparative study. Obes Surg 2013;23(3):353-7.

[13] Shiloach M, Frencher Jr SK, Steeger JE, et al. Toward robust information: data quality and inter-rater reliability in the American College of Surgeons National Surgical Quality Improvement Program. J Am Coll Surg 2010;210(1):6-16.

[14] Ogden CL, Carroll MD, Fryar CD, Flegal KM. Prevalence of obesity among adults and youth: United States, 2011-2014. NCHS Data Brief 2015;(219):1-8.
[15] Wang Y, Beydoun MA. The obesity epidemic in the United Statesgender, age, socioeconomic, racial/ethnic, and geographic characteristics: a systematic review and meta-regression analysis. Epidemiol Rev 2007;29:6-28.

[16] Flegal KM, Carroll MD, Ogden CL, Curtin LR. Prevalence and trends in obesity among US adults, 1999-2008. JAMA 2010;303(3):235-41.

[17] Steele CB, Thomas CC, Henley SJ, et al. Vital signs: trends in incidence of cancers associated with overweight and obesity - United States, 2005-2014. MMWR Morb Mortal Wkly Rep 2017;66(39):1052-8.

[18] Tarasiuk A, Mosinska P, Fichna J. The mechanisms linking obesity to colon cancer: an overview. Obes Res Clin Pract 2018;12(3):251-9.

[19] McNabney SM, Henagan TM. Short chain fatty acids in the colon and peripheral tissues: a focus on butyrate, colon cancer, obesity and insulin resistance. Nutrients 2017;9(12):1348.

[20] Alizadeh RF, Moghadamyeghaneh Z, Whealon MD, et al. Body mass index significantly impacts outcomes of colorectal surgery. Am Surg 2016;82(10):930-5.

[21] Causey MW, Johnson EK, Miller S, Martin M, Maykel J, Steele SR. The impact of obesity on outcomes following major surgery for Crohn's disease: an American College of Surgeons National Surgical Quality Improvement Program assessment. Dis Colon Rectum 2011;54(12):1488-95.

[22] McKenna NP, Mathis KL, Khasawneh MA, et al. Obese patients undergoing ileal pouch-anal anastomosis. Inflamm Bowel Dis 2017;23(12):2142-6.

[23] Acosta LF, Garcia CR, Dugan A, Marti F, Davenport D, Gedaly R. Impact of super obesity on perioperative outcomes after hepatectomy: the weight of the risk. Surgery 2017;162(5):1026-31.

[24] Augustin T, Moslim MA, Brethauer S, et al. Obesity and its implications for morbidity and mortality after cholecystectomy: a matched NSQIP analysis. Am J Surg 2017;213(3):539-43.

[25] Jokinen E. Obesity and cardiovascular disease. Minerva Pediatr 2015;67(1):25-32.

[26] Despres JP, Lemieux I. Abdominal obesity and metabolic syndrome. Nature 2006;444(7121):881-7.

[27] Tinelli A, Malvasi A, Mynbaev OA, et al. Bladeless direct optical trocar insertion in laparoscopic procedures on the obese patient. JSLS 2013;17(4):521-8.

[28] Watanabe J, Tatsumi K, Ota M, et al. The impact of visceral obesity on surgical outcomes of laparoscopic surgery for colon cancer. Int J Colorectal Dis 2014;29(3):343-51.

[29] Lascano CA, Kaidar-Person O, Szomstein S, Rosenthal R, Wexner SD. Challenges of laparoscopic colectomy in the obese patient: a review. Am J Surg 2006;192(3):357-65.

[30] Daley BJ, Cecil W, Clarke PC, Cofer JB, Guillamondegui OD. How slow is too slow? Correlation of operative time to complications: an analysis from the Tennessee Surgical Quality Collaborative. J Am Coll Surg 2015;220(4):550-8.

[31] Cawley J, Sweeney MJ, Kurian M, Beane S. Predicting complications after bariatric surgery using obesity-related co-morbidities. Obes Surg 2007;17(11):1451-6.

[32] Wagner IJ, Szpalski C, Allen Jr RJ, et al. Obesity impairs wound closure through a vasculogenic mechanism. Wound Repair Regen 2012;20(4):512-22.

[33] Doyle SL, Lysaght J, Reynolds JV. Obesity and post-operative complications in patients undergoing non-bariatric surgery. Obes Rev 2010;11(12):875-86.

[34] Springer JE, Doumouras AG, Eskicioglu C, Hong D. Regional variation in the utilization of laparoscopy for the treatment of rectal cancer: the importance of fellowship training sites. Ann Surg Oncol 2020;27(7):2478-86.

[35] Disbrow DE, Pannell SM, Shanker BA, et al. The effect of formal robotic residency training on the adoption of minimally invasive surgery by young colorectal surgeons. J Surg Educ 2018;75(3):767-78. 